JLAS, 8(1), 1998, 24-32

(C) 1998 The Society for the Study of the Legal Aspects of Sport and Physical Activity

\title{
Risk Management Study of NCAA Division II Athletic Directors
}

\author{
by \\ David A. Brown, M.S. \\ and \\ Thomas H. Sawyer, Ed.D., Professor \\ Department of Recreation and Sport Management \\ Indiana State University \\ Terre Haute, IN 47809
}

812/237-2186; FAX 812/237-4337; Email pmsawyer@scifac.indstate.edu

\begin{abstract}
This study researched the risk management practices of NCAA Division II athletic directors. A 36-item questionnaire was distributed to 247 Division II athletic directors, the questionnaire contained items from the following five areas, personnel, transportation, facilities, emergency procedures, and equipment. The survey achieved a response rate of $75 \%$ with 186 questionnaires returned, 51 returned surveys were not usable.

The questionnaire responses were tested in the following areas, the size of the athletic department (coaches, trainers, and administrators), funding sources (public or private), football as a varsity sport, and the geographic location of the college or university.

Significant differences were found in all areas, with the greatest differences occurring between colleges and universities that have football as a varsity sport and those that do not. The area of investigation that had the greatest number of significant differences was equipment, with differences occurring in all areas that were tested.
\end{abstract}

\section{INTRODUCTION}

In the world of intercollegiate athletics, the subject of risk management is not front page news for most universities. Risk management will not directly affect attendance, enrollment, winning, or post season play in the eyes of most administrators in college athletics. Risk management will in fact play a role in these areas when the practice of risk management is not carried out properly. If a spectator or athlete is injured by a negligent act of a university, the law suit that will follow impacts all aspects of the athletic program and university. The athletic director at a college or university is held responsible for the risk management program used in con- junction with intercollegiate athletics. The athletic director is ultimately responsible for any negligent acts committed in an athletic program.

The study of risk management at the college level is not new. In 1993, Gray and Crowell studied the risk management practices of NCAA Division I athletic directors, and in 1994, Anderson and Gray conducted a study of NCAA Division III athletic directors. However, no study to date has focused on NCAA Division II athletic directors, a growing section of college athletics.

These studies used several different conceptual areas to analyze the risk management behaviors of the athletic directors in their respective Divisions. The areas of investigation used 
in this study were the following, personnel, transportation, facilities, emergency procedures, and equipment. Each one of these areas should be an important risk management concern for Division II athletic departments. The previous studies have investigated these and other areas, offering a chance for comparison and discussion.

Previous studies conducted at the college level have concentrated on risk management performances based upon the demographic factors of the athletic directors. These studies did find significant differences based on these factors. In Division I athletics significant differences were found in the following factors: participation in intercollegiate athletics, intercollegiate coaching status, and their major fields of academic study (Gray \& Crowell, 1993). In Division III athletics one significant difference was found based upon the coaching status of athletic directors (Gray \& Anderson, 1994).

These studies have concentrated on the athletic director's personal characteristics. They paid no attention to the characteristics of the college or university in which the athletic department operates. The school can play a significant role in the risk management program of an athletic department.

This study evaluated the risk management performance of athletic directors in NCAA Division II schools based upon demographic characteristics of the institutions, not of the athletic directors. Specifically, the study concentrated on institutional characteristics that can have an influence on how well risk management is performed. The following characteristics were studied, the size of an institution's athletic budget, the size of the institution's athletic department, whether an institution is public or private, and whether it has football as a varsity sport. This study divided the country into six separate regions to see if risk management differs across the geographic locations of schools. This was valuable in determining whether or not risk management is influenced by the different political and social views throughout the country.

\section{Statement of Problem}

Earlier in the field of intercollegiate risk management, have focused on athletic directors at the Division I and III levels. These studies have looked at the demographic factors of the athletic directors and used that information to find significant differences in their performance levels. These studies have not taken into account the colleges and universities in which the athletic directors operate their departments. This study concentrated on NCAA Division II athletic directors and how they manage risk containment. The demographic factors of the college or university were used to analyze the data collected during the study.

\section{Delimitations}

This study was limited to the following: (1) only athletic directors at the NCAA Division II level were included in the study; and (2) the requirements for participation in this study as an NCAA Division II athletic director was based upon an institution being listed as NCAA Division II in the 1996-97 National Directory of College Athletics, men's edition.

\section{Limitations}

The following limitations existed in this study: (1) the listing of NCAA Division II athletic directors contained in the 1996-97 National Directory of College Athletics, men's edition is accurate; and (2) questionnaire items are perceived by the athletic directors as intended by the researcher.

\section{Assumptions of the Study}

The following assumptions are required in order for this study to be completed: (1) the surveys sent out the athletic directors would be returned in a timely manner; (2) the surveys were answered correctly and truthfully; and (3) there is a significant difference in performance levels based upon the mentioned demographic factors for Division II athletic directors.

\section{Hypotheses}

The following hypotheses were used in this study: (1) the size of an athletic department's budget will have no significant effect on the performance of risk management; (2) the size of the athletic department (coaches, trainers, ad administrators) will have no significant effect on the performance of risk management; (3) the funding source (public or private) of a college or university will have no significant effect on risk management; (4) a college or university having football as a varsity sport will have no 
significant effect on risk management; and (5) the geographic location of a college or university will have not significant effect on risk management.

\section{Operational Definitions}

Risk Management Behavior: A risk management behavior is an observable action that takes place within an athletic department, and concerns the area of risk management. These actions do not have to be performed by the athletic director; but since the athletic director is ultimately responsible for what happens in an athletic department, they should be able to verify whether or not an action has been accomplished and documented.

Performance Levels: The performance levels in this study were related to the questionnaire responses given by the athletic directors. The responses were based on a five point Likert scale ranging from one to five, where one indicated the behavior is never performed and five indicates a behavior is always performed.

\section{Significance of Study}

This study filled a gap that has been left in the study of risk management at the collegiate level. Previous studies have focused on NCAA Division I and II levels, Division II has not been studied. This allows for future studies to be conducted using all three studies to draw conclusions about how risk management is practiced at all levels of NCAA competition. This study established a baseline for risk management in NCAA Division II athletics. This allows for future research to be conducted in Division II athletics to see if risk management performance has changed.

\section{Research Design}

This study reviewed the risk management behaviors of NCAA Division II athletic directors. A questionnaire was distributed to all NCAA Division II athletic directors. This questionnaire had questions that dealt with the five areas of investigation used in this study. The questionnaire used a five point Likert scale to represent how often a risk management behavior was performed. The scale ranged from one indicating the behavior was never performed to five where the behavior was always performed. A pilot study was conducted to test the validity of the questionnaire to Division II athletics.

Sample

All NCAA Division II athletic directors were used in the study. A list of all Division II athletic directors was compiled by using the 1996-97 National Directory of College Athletics, men's edition. Only NCAA Division II schools listed in the publication were used in this study. The sample of schools was arranged into six geographic regions by the researcher. The researcher attempted to keep socioeconomic as well as physical regions of the country together. Questionnaire

A questionnaire was developed for distribution to Division II athletic directors. The questionnaire used a five point Likert scale to represent how often a behavior was performed (1never performed, 2-seldom performed, 3- sometimes performed, 4- often performed, and 5always performed). The questions used in the survey were a combination of questions found in previous risk management studies (Gray \& Cromwell, 1993; Gray \& Anderson, 1994) conducted in college athletics, and was developed from points made during the discussion of the five areas of investigation in this study.

Pilot Study

A pilot study was conducted using a selected sample of NCAA Division II athletic directors to test the validity of the survey. Questionnaires and return envelopes were sent to fifteen selected NCAA Division II athletic directors. The pilot study had a return rate of $60 \%$. Two changes were made to the original survey based on responses given during the pilot study. The statistical model for this study was also tested during the pilot study.

\section{Procedures}

The first mailing was designed to announce a week in advance that a survey would be arriving. Next, the questionnaire and a cover letter, including a pre-stamped return envelope, were sent to each athletic director using conventional mail. Two weeks after the questionnaires were mailed, a follow-up mailing was distributed to athletic directors who had not responded. This follow-up mailing consisted of a second questionnaire and a pre-stamped return envelope. This was the only follow-up mailing sent. 


\section{Statistical Analysis}

The statistical analysis used in this study was a one-way analysis of variance (ANOVA) using the Scheffe post-hoc test and an independent samples t-test. The analysis to be used depended on the number of groups being compared. This use of parametric statistics was in keeping with published studies in this area. A generic hypothesis was used to test the results of the selected demographic factors (e.g., $\mathrm{H}_{\mathrm{o}}$-the performance of private institutions $=$ the performance of public institutions, $\mathrm{H}_{\mathrm{A}}$-the performance of private institutions $\neq$ the performance public institutions). The results of the statistical analysis were considered significant at the $p<.05$ level of significance.

\section{Response Rate}

Questionnaires were distributed to 247 NCAA Division II athletic directors. The total number of responses was 186 equaling a $75 \%$ return rate. Fifty-one returned questionnaires were found to be not usable.

\section{Statistical Analysis}

The responses from the questionnaire were tested statistically using the following hypothesis:

1. The size of an athletic department budget will have no significant effect on risk management.

2. The size of the athletic department (coaches, trainers, and administrators) will have no significant effect on risk management.

3. The funding source (public or private) of a college or university will have no significant effect on risk management.

4. A college or university having football as a varsity sport will have no significant difference on risk management.

5. The geographic location of a college or university will have no significant effect on risk management.

The results of the statistical analysis were separated into the following groups, budget size, athletic department size, funding source, football as a varsity sport, and geographic regions. The tern outperformed was used in reporting the results of this study to indicate when one group surpassed another group in performance. The performance levels in this study were related to the questionnaire responses given by the athletic directors. The responses were based on a five point Likert scale ranging from one to five, where one indicated the behavior was never performed and five indicated the behavior was always performed.

- Budget Size This statistical test was not conducted because the information received from the questionnaires was incomplete.

- Athletic Department Size Athletic departments were separated into three groups by the size of their athletic department. The athletic departments ranged in size from 8 to 70 people. The groups consisted of the following: Group 1, 8 to 20 people; Group 2, 21 to 31 people; and Group 3, 32 to 70 people. Each item from the questionnaire was tested with these three groups using an ANOVA with a Scheffe post-hoc test to identify differences. The following significant differences were found:

- Equipment inspections were documented in writing with an $F(2,132)=5.3161, p=.006$. The Scheffe showed that Group $3 \quad(m=3.93)$ outperformed Group $2(\mathrm{~m}=3.66)$ and Group $1(\mathrm{~m}=3.1)$.

- Athletes were educated on proper use of equipment with an $F(2,132)=3.1235$, $p=.0473$. The Scheffe showed that Group $3(m=4.81)$ outperformed Group $2(\mathrm{~m}=4.64)$ and Group $1(\mathrm{~m}=4.51)$.

- Equipment was stored and maintained according to the manufacturer's guidelines with an $F(2,132)=6.3187$, $\mathrm{p}=.0024$. The Scheffe showed that Group $3(\mathrm{~m}=4.57)$ outperformed Group $2(m=4.3)$ and Group $1(m=4.0)$.

- Independent contractors were used to transport athletic teams with an $F(2,132)=13.4206, p=.0001$. The Scheffe test indicated that Group 3 $(m=3.4)$ and Group $2(m=3.25)$ outperformed Group $1(\mathrm{~m}=2.45)$.

- Funding Source Colleges and universities were separated into two groups based on how they indicated they were funded (public, $n=76$ or private, $n=59$ ). The items 
from the questionnaire were tested using independent samples t-test. The following significant differences were found:

- A comprehensive personnel screening systern exists in the athletic program. Public programs $(m=4.25, s d=.95)$ outperformed private programs $(m=3.85, s d=1.11)$, with a $t(133)=2.26$, $\mathrm{p}=.025$.

- School owned vehicles have inspections and maintenance documented in writing. Public programs $(m=4.72$, $s d=.6$ ) outperformed private programs $(m=4.15, \quad s d=1.36)$, with a $\mathrm{t}(75.59)=3.00, \mathrm{p}=.004$.

- Facilities were thoroughly inspected prior to events. Public programs $(m=4.07$, $\mathrm{sd}=.88$ ) outperformed private programs $(\mathrm{m}=3.71, \mathrm{sd}=.87)$, with $\mathrm{t}(133)=2.32$, $\mathrm{p}=.022$.

- Facilities evacuation procedures had been developed. Public programs $(\mathrm{m}=4.01, \mathrm{sd}=1.11)$ outperformed private schools $(m=3.51, s d=1.33)$, with a $\mathrm{t}(133)=2.4, \mathrm{p}=.018$.

- Personnel involved in the emergency response plan know their job responsibilities. Public programs $(\mathrm{m}=4.25, \mathrm{sd}=.94)$ outperformed private programs $(m=3.73, s d=1.23)$, with a $\mathrm{t}(105.74)=2.70, \mathrm{p}=.008$.

- Emergency phone numbers were posted at telephones. Public programs ( $m=4.18, s d=1.09$ ) outperformed private programs $(m=3.73, s d=1.11)$, with a $\mathrm{t}(133)=2.38, \mathrm{p}=.018$.

- Records of reconditioning (equipment) were kept on file, including the receipt, invoice, or purchase order used in the reconditioning. Public programs ( $m=4.38, s d=1.02$ ) outperformed private programs $(m=3.92, s d=1.42)$, with a $\mathrm{t}(101.28)=2.13, \mathrm{p}=.035$.

- Football as a Varsity Sport Colleges and universities were separated into two separate groups based on whether the athletic program offered football as a varsity sport. The programs that offered football $(n=74)$ and the programs that do not offer football $(n=61)$ were tested against each questionnaire item using independent samples t-test. The significant results were as follows:

- How often was the maximum seating capacity in stands or arena exceeded? Non-football programs $(m=1.36, \mathrm{sd}=.68)$ outperformed football programs $(m=1.74, \quad s d=.88)$, with a $t(132.62)=2.85, p=.005$.

- Athletic equipment was inspected regularly. Football programs $(m=4.7$, $\mathrm{sd}=.57$ ) outperformed non-football programs $(m=4.48, s d=.7)$, with a $\mathrm{t}(115.06)=2.05, \mathrm{p}=.043$.

- Job descriptions were developed for all positions in the athletic department. Non-football programs $(\mathrm{m}=4.8, \mathrm{sd}=.51)$ outperformed football programs $(m=4.51, \quad s d=.88)$, with a $t(120.39)=2.39, p=.019$.

- Equipment inspections were documented in writing. Football programs $\quad(m=3.83, \quad s d=1.18)$ outperformed non-football programs $(m=3.18, \quad s d=1.31)$, with a $t(133)=3.06, p=.003$.

- Equipment was reconditioned when necessary. Football programs $(m=4.84$, $s d=.37$ ) outperformed non-football programs $(m=4.2, s d=.98)$, with a $\mathrm{t}(74.17)=4.83, \mathrm{p}=.001$.

- Records of reconditioning (equipment) were kept on file, including the receipt, invoice, or purchase order used in the reconditioning. Football programs $(m=4.64, s d=.69)$ outperformed nonfootball programs $(m=3.62, s d=1.49)$, with a $\mathrm{t}(81.37)=4.90, \mathrm{p}=.001$.

- Equipment was stored and maintained according to the manufacturer's guidelines. Football programs $(m=4.46$, $s d=.65$ ) outperformed non-football programs $(m=4.05, s d=.9)$, with a $\mathrm{t}(133)=3.07, \mathrm{p}=.003$.

- Defective or damaged athletic equipment was rendered useless. Football programs $(m=4.78, s d=.48)$ 
outperformed non-football programs $(m=4.56, \mathrm{sd}=.74)$, with a $\mathrm{t}(98.30)=2.06$, $\mathrm{p}=.042$.

- Coaches, administrators, and trainers were required to attend in house training sessions. Non-football programs $(\mathrm{m}=4.33, \mathrm{sd}=.85$ ) outperformed football programs $(m=3.89, s d=1.02)$, with a $\mathrm{t}(133)=2.67, \mathrm{p}=.009$.

- Independent contractors were used to transport athletic teams. Football programs $\quad(m=3.34, \quad s d=.94)$ outperformed non-football programs $(m=2.61, s d=1.02)$, with a $t(133)=4.33$, $\mathrm{p}=.001$.

- Geographic Regions The country was divided into six geographic regions (see Map 1). The researcher attempted to keep socioeconomic as well as physical regions of the country together. Each questionnaire item was tested using an ANOVA with these six groups. A Scheffe post-hoc test was used to identify the statistical differences. The significant differences are as follows:

- Athletic equipment met relevant safety standards ((i.e., National Operating Committee on Standards for Athletic Equipment (NOCSAE), Canadian Standards Association (CSA), Hockey Equipment Certification Council, (HECC), or American Society for Testing Materials (ASTM)) with an $F(5,129)=2.9894, p=.0138$. The Scheffe test revealed that Region $1(\mathrm{~m}=4.89)$ and Region $4(m=4.9)$ outperformed Region $3(m=4.86)$, Region $2(m=4.82)$, Region $6(m=4.8)$, and Region $5(m=4.33)$.

\section{Discussion}

The discussion of the results is divided into five groups. The five groups were, budget size, athletic department size, finding sources, football as a varsity sport, and geographic regions.

Budget Size. This test was not conducted because the data received from the athletic directors was incomplete or inconsistent. The researcher was looking for a general number that represented the complete athletic budget for the whole program. Some athletic directors only report operational budgets or budgets for salaries and wages. A great number of athletic directors chose not to disclose a budget figure. A higher response to this questionnaire item might have been achieved if the request was more descriptive, such as what is the operational budget of your athletic department excluding scholarships and outside contributions.

Athletic Department Size Athletic departments were put into three groups according to the size of their athletic departments. The groups consisted of the following: Group 1, 8 to 20 people; Group 2, 21 to 31 people; and Group 3, 32 to 70 people. Group 3 outperformed the other two groups in the area of equipment, specifically the areas, equipment inspections are documented in writing, athletes are educated on the proper use of equipment, and equipment is stored and maintained according to the manufacturer's guidelines. This finding can be attributed to the fact that larger athletic departments have more employees to handle such jobs. A large number of athletic departments also have a full time equipment manager to handle these areas as well as any other equipment related concerns.

Another significant finding was found in the area of transportation, specifically the use of independent contractors to transport athletic teams. Groups 3 and 2 outperformed Group 1 in this area. This can be attributed to larger athletic departments having the funds to use independent contractors while smaller programs must use transportation that is organic to the school.

Funding Source Colleges and universities were separated into two groups based on how they indicated they were funded (public or private). Significant differences were found in the following five areas of investigation, personnel, transportation, facilities, emergency procedures, and equipment. In the area of personnel, the difference existed in whether a comprehensive personnel screening system existed in the athletic program. The questionnaire responses indicated that athletic directors at public schools used a personnel screening system more often 
than athletic directors at private schools.

In the area of transportation, the following significant difference existed. School owned vehicles have inspections and maintenance documented in writing. The questionnaire results indicated that public schools documented inspections and maintenance more often than private schools.

In the area of facilities, two significant differences were found as follows: facilities were thoroughly inspected prior to events, and facility evacuation procedures had been developed. In both of these, public schools outperformed private schools.

In the area of emergency procedures, two significant differences were found as follows, personnel involved in the emergency response plan know their job responsibilities, and emergency phone numbers are posted at telephones. Public schools outperformed private schools in both of these items.

A significant difference existed in the area of equipment. The difference existed in whether records of reconditioning (equipment) were kept on file, with the receipt, invoice, or purchase order used in the reconditioning on file more often than private schools.

These differences can be caused by the fact that public colleges and universities operate in a more formalized environment than private colleges. Public schools have more rules and regulations governing their actions than private schools are audited for safety and for fiscal concerns more often than private schools.

Football as a Varsity Sport The colleges and universities that responded to the questionnaire were placed into two separate groups based on whether or not they offered football as a varsity sport. Significant differences were found in the following area, equipment, transportaition, personnel, and facilities. The greatest differences were found in the area of equipment, the differences included, athletic equipment is inspected regularly, equipment inspections are documented in writing, equipment is reconditioned when necessary, records of reconditioning (equipment) are kept on file, with the receipt, invoice, or purchase order used in the reconditioning, equipment is stored and maintained according to the manufacturer's guidelines, and defective or damaged equipment is rendered useless. The schools with football programs outperformed non-football programs in each of these items. Since football is an equipment intensive sport, programs that offer it will pay a great deal of attention to the quality and care of the equipment that the student athletes use.

In the area of transportation, the significant difference was found in the use of independent contractors. Schools that offer football indicated that they use independent contractors to transport athletic teams more often than schools that do not offer football. Football teams are usually the largest teams in a school, which includes players as well as staff that will travel with the team. The use of independent contractors to transport a large number of people is safer and more economically efficient than attempting to transport them with vans and other school owned vehicles.

Two significant differences were found in the area of personnel. These differences were: (1) job descriptions are developed for all positions in the athletic department, and (2) coaches, administrators, and trainers are required to attend in house training sessions. In both of these items non-football programs outperformed football programs. There is no logical reason why there is a difference in these areas. Schools that offer football should have detailed job descriptions for each member of the athletic department. In a severe contact sport such as football, there si a higher injury rate than in other varsity sports; therefore in house training sessions should be mandatory for all members of the athletic staff, especially those directly involved with football.

In the area of facilities, the significant difference was found in how often the maximum seating capacity in stands or arena is exceeded. Schools that do not have football programs outperformed schools with football programs in this area. This can occur since varsity football at the college level is a very popular spectator sport. The practice of exceeding the seating capacity of stands is very dangerous. If spectators were 
injured because in an emergency situation there were too many people to accomplish an evacuation of a stadium or stands in a safe or timely manner, the repercussions would be serous. Another concern would be the collapsing of the stands because they were overloaded. The lawsuit that would occur from this would severely damage the reputation of any school.

Geographic Regions There was only one significant difference found when all questionnaire items were tested by geographic region. The difference existed in the area of equipment, specifically the following item, athletic equipment meets relevant safety standards (i.e., National Operating Committee on Standards for Athletic Equipment (NOCSAE), Canadian Standards Association (CSA), Hockey Equipment Certification Council (HECC), or American Society for Testing Materials (ASTM)). Regions 1 and 4 outperformed the other four regions on this item. The questionnaire results indicated that the equipment, in these two regions, meets relevant safety standards more often than the other regions. Further, investigation into the regions may explain why this happened. Regions, 1 and 4 had more schools that had varsity football in their athletic programs; schools with football programs outperformed schools without football programs in the area of equipment. Region 1 consisted of schools in the Northeast section of the country. These schools also have ice hockey and lacrosse programs which other sections of the country do not have or have limited participation. These sports are contact sports that require protective equipment, especially helmets. For safety reasons these schools would provide their student athletes with quality protective equipment, especially assuring their helmets meet all required safety standards.

\section{Conclusions}

The statistical means for the questionnaire items were mostly in the range of often, meaning the risk management behavior was often performed. There are some areas that need to be developed in Division II athletics. Specifically, the following items had means in the range of seldom, indicating the behavior was seldom performed: (1) emergency response plan is prac- ticed or rehearsed, and (2) practice or rehearsal of emergency response plan is documented in writing.

These weaknesses deal with the area of emergency response planning. The emergency response plan should be practiced or rehearsed in order to: 1) find communication problems, and 2) ascertain if the plan is effective in dealing with all emergencies that can occur in athletics. The practice or rehearsal of the emergency response plan should be documented. Documentation of practice sessions will help: 1) identify weaknesses that need to be corrected, and 2) establish adherence to an expected standard of care if a law suit should occur (Herbert, 1995; Herbert, 1994).

There were also some very important risk management items that scored in the sometimes range, indicating that the behavior is sometimes performed. These questionnaire items consist of the following:

1. drivers of school owned vehicles have a chauffeurs license,

2. facility inspections are documented in writing,

3. equipment inspections are documented in writing,

4. guides or escorts are used to direct emergency personnel to the site where they are needed,

5. facility evacuation procedures have been developed, and

6. facility inspections prior to events are thorough.

Regular inspections should be completed and documented. Inspections play a vital role in any risk management program, athletic directors can be liable for any dangerous situation of which they know of or should have known of if a professional job had been done on inspections (van der Smissen, 1990). Failing to document the inspection of equipment and facilities will not help an athletic director or coach should a law suit occur.

\section{Recommendations for Further Research}

The following are recommendations for further research on this topic:

1. A study using the demographic factors of the athletic directors similar to the previous 
studies (Gray \& Cromwell, 1993; Gray \& Anderson, 1994) to get the total picture of risk management in Division II athletics.

2. Conducting a study similar to this one using NCAA Division I and III athletic directors to see if the same differences exist in those athletic departments.

3. Combining this study, the previous studies, and the studies listed above to get a total picture of risk management in college athletics.

4. Studies using geographic regions to see if different aspects of college athletics are affected by socioeconomic or political differences throughout the country.

\section{References}

Anderson, M., \& Gray, G. (1994). Risk management behaviors in NCAA division III athletic programs. Lournal of Legal Aspects of Sport, 4, (1), 78-84.

Arnheim, D.D., \& Prentice, W.E. (1993). Principles of athletic training (8th ed.). St. Louis, MO: Mosby Year Book.

Berry, R.C., \& Wong, G.M. (1986). Law and business of the sports industries, common issues in amateur and professional sports. (Vol. II). Dover, MA: Auburn House Publishing Company.

Champion, W.T., Jr. (1993). Sports law in a nutshell St. Paul, MN: West Publishing Company.

Clement v. Griffen, 634 So.2d 412 (La. App. 4 Cir. 1994).
Cotten, D.J. (1993), risk management- a tool for reducing exposure to legal liability. Lournal of Physical Education. Recreation, and Dance, 64, (2), 58-61.

Gray, G., \& Cromwell, S. (1993). Risk management behaviors in NCAA division I athletic programs. Lournal of Legal Aspects of Sport, 3, (2), 64-70.

Hall, R.G., \& Kanoy, R. (1995). A study of public schools systems hiring practices relating to the use of criminal background checks. Lournal of Legal Aspects of Sport, $5,(1), 60-68$.

Herbert, J.D. (1995). Developing a comprehensive sports emergency response plan. The Sports, Parks \& Recreation Law Reporter, 9, (2), 23.

Herbert, J.D. (1994). Emergency response planning for administrators and coaches. The Sports, Parks \& Recreation Law Reporter, 7, (4), 49-52.

Lehr, C. (1994). Use of vans... take extra precaution. The Sports, Parks \& Recreation Law Reporter, 8, (3), 38-39.

Miller, L.K., Fielding, L.W., \& Pitts, B.G. (1993). Hiring concerns impacting the sport practitioner. Lournal of Legal Aspects of Sport, 4, (1), 18-28.

Schubert, G.W., Smith, R.K., \& Trentadue, J.C. (1986). Sports Law. St. Paul, MN: West Publishing Company.

van der Smissen, B. (1990). Legal liability and risk management for public and private entities. Cincinnati, $\mathrm{OH}$ : Anderson Publishing Co.

Wong, G.M. (1994). Essentials of Amateur Sports Law (2nd ed.). Westport, CT: Praeger.

Woodring v. The Board of Education of Manhasset Union Free School District, Etc. App.

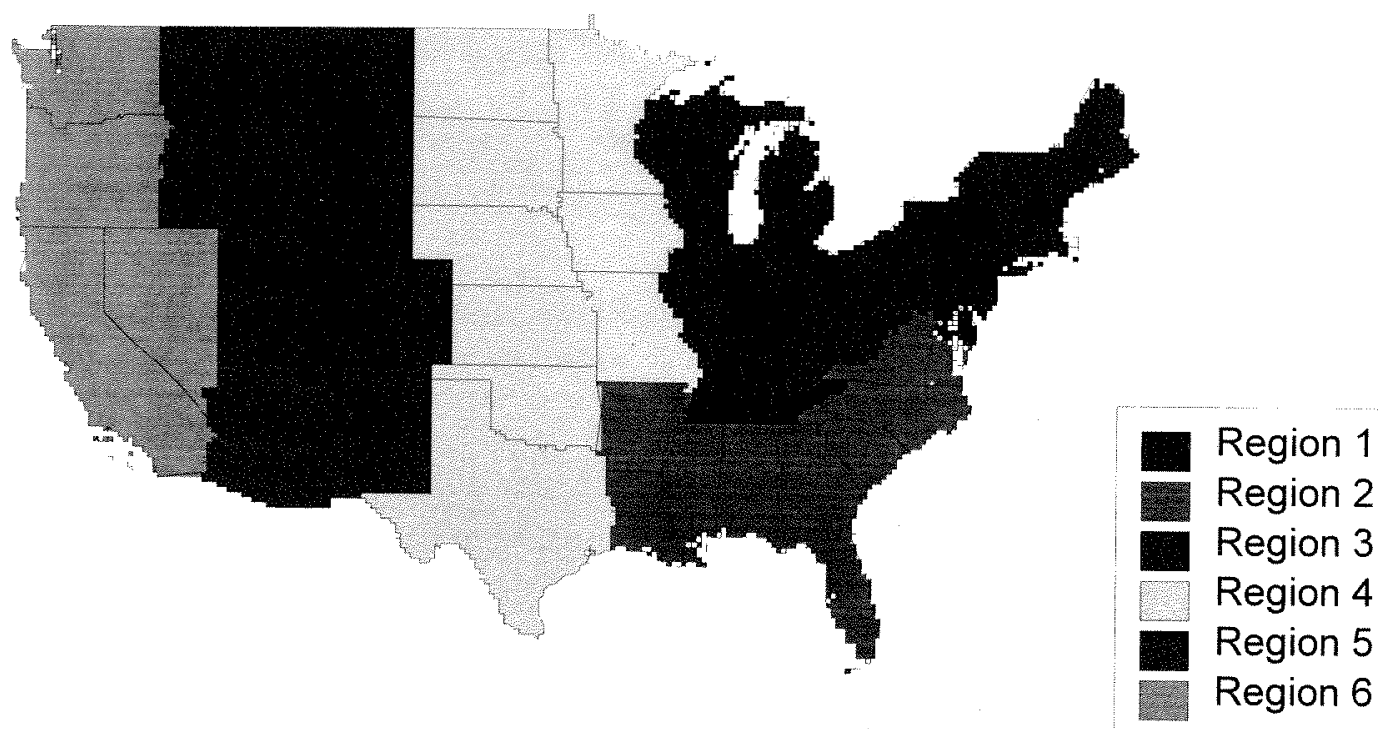

